University of Nebraska - Lincoln

DigitalCommons@University of Nebraska - Lincoln

Faculty Publications from Nebraska Center for Research on Children, Youth, Families, and Schools
Children, Youth, Families \& Schools, Nebraska Center for Research on

2010

\title{
Family involvement for children with disruptive behaviors: The role of parenting stress and motivational beliefs
}

\author{
Carrie A. Semke \\ University of Nebraska - Lincoln, cblevins@huskers.unl.edu \\ S. Andrew Garbacz \\ University of Nebraska-Lincoln, andy.garbacz@wisc.edu \\ Kyongboon Kwon \\ University of Nebraska-Lincoln \\ Susan M. Sheridan \\ University of Nebraska-Lincoln, ssheridan2@unl.edu \\ Kathryn Woods \\ University of Nebraska-Lincoln, kwoods@huskers.unl.edu
}

Follow this and additional works at: https://digitalcommons.unl.edu/cyfsfacpub

Part of the Child Psychology Commons, Counseling Psychology Commons, Developmental

Psychology Commons, Family, Life Course, and Society Commons, and the Other Social and Behavioral

Sciences Commons

Semke, Carrie A.; Garbacz, S. Andrew; Kwon, Kyongboon; Sheridan, Susan M.; and Woods, Kathryn, "Family involvement for children with disruptive behaviors: The role of parenting stress and motivational beliefs" (2010). Faculty Publications from Nebraska Center for Research on Children, Youth, Families, and Schools. 102.

https://digitalcommons.unl.edu/cyfsfacpub/102

This Article is brought to you for free and open access by the Children, Youth, Families \& Schools, Nebraska Center for Research on at DigitalCommons@University of Nebraska - Lincoln. It has been accepted for inclusion in Faculty Publications from Nebraska Center for Research on Children, Youth, Families, and Schools by an authorized administrator of DigitalCommons@University of Nebraska - Lincoln. 


\title{
Family involvement for children with disruptive behaviors: The role of parenting stress and motivational beliefs
}

\author{
Carrie A. Semke, S. Andrew Garbacz, Kyongboon Kwon, \\ Susan M. Sheridan, and Kathryn E. Woods \\ Nebraska Center for Research on Children, Youth, Families and Schools, Department of \\ Educational Psychology, University of Nebraska-Lincoln, Lincoln, Nebraska, USA \\ Corresponding author - C.A. Semke, Department of Educational Psychology, 114 Teacher's College Hall, \\ University of Nebraska-Lincoln, Lincoln, NE 68588-0345, USA; tel 402 802-3047, fax 402 472-8319, \\ email cblevins@huskers.unl.edu
}

\begin{abstract}
Children with disruptive behaviors are at risk for adverse outcomes. Family involvement is a significant predictor of positive child behavior outcomes; however, little research has investigated parent psychological variables that influence family involvement for children with disruptive behaviors. This study investigated the role of parental motivational beliefs (i.e., role construction and efficacy) as a potential mechanism by which parenting stress impacts family involvement for families of children with disruptive behaviors. Results indicated that parent role construction mediated the relation between parenting stress and all aspects of family involvement examined (i.e., home-based involvement, school-based involvement, and home-school communication). Parent efficacy mediated the relation between parenting stress and home-based involvement only. Parents of children with disruptive behaviors reporting stress may experience negative beliefs about their role and efficacy to support their child's education, which may thereby negatively influence their actual involvement. Therefore, parent motivational beliefs may serve as an important point for intervention to support involvement of families of children with disruptive behavior.
\end{abstract}

Keywords: Family involvement, Disruptive behavior, Parenting stress

\footnotetext{
This research is supported by a grant awarded to Drs. Susan Sheridan and Todd Glover by the U.S. Department of Education, Institute of Educational Sciences (Grant \# R305Fo50284). The opinions expressed herein are those of the investigators and do not reflect the funding agency. We are appreciative of the cooperation of the administrators, teachers, parents, and students who participated in this study, as their involvement in research is the cornerstone to uncovering important educational findings.
} 
S tudents with disruptive behaviors pose a significant concern for families, schools, and society. Specifically, students with disruptive behaviors experience a greater number of academic difficulties including in-school suspensions (Reinke, Herman, Petras, \& Ialongo, 2008), high school drop-out (Vitaro, Brendgen, Larose, \& Trembaly, 2005), as well as lower academic grades and achievement scores (Bub, McCartney, \& Willett, 2007; Lopes, 2007). These students also demonstrate higher rates of risk factors including school maladjustment, antisocial activity, substance use, sexual activity (Schofield, Bierman, Heinrichs, \& Nix, 2008), and conduct problems (Reinke et al., 2008). Because students with behavior problems are at increased risk for experiencing a variety of negative life outcomes, it is vital to identify risk and resiliency factors and the mechanisms by which such factors exert their influence.

Family involvement is defined as the active engagement of family members in activities and behaviors at home and at school to benefit their child's learning and development (Fantuzzo, Tighe, \& Childs, 2000). Family involvement in children's learning is related to a number of positive academic, psychological, social, and behavioral outcomes for all children, including those with disruptive behaviors (Aeby, Manning, Thyer, \& Carpenter-Aeby, 1999; Barnard, 2004; Grolnick \& Slowiaczek, 1994; Ma, 1999; Marcon, 1999; Miedel \& Reynolds, 1999; Trusty, 1999). Family involvement activities have been shown to prevent children's behavioral problems (Domina, 2005) and are associated with positive academic outcomes, including increased academic achievement and motivation for schoolwork (e.g., Comer \& Haynes, 1991; Grolnick \& Slowiaczek, 1994), lower rates of grade retention, lower drop-out rates, higher on-time high school graduation rates, and higher rates of participation in advanced courses (e.g., Barnard, 2004; Ma, 1999; Marcon, 1999; Miedel \& Reynolds, 1999; Trusty, 1999). Furthermore, students with disruptive behaviors whose family participated in an intervention to increase family involvement demonstrated improved grade point averages, attendance, and reduced drop-out rates relative to students participating in a standard program (Aeby et al., 1999), indicating the powerful effect of family involvement on student outcomes. Particularly, the frequency and quality of family-school communication have been identified as an important predictor of child social and academic functioning in school (Christenson \& Sheridan, 2001; Izzo, Weissberg, Kasprow, \& Fendrich, 1999).

\section{Conceptual model}

Given that family involvement at home and school is the outward manifestation of parents' behaviors in support of their child's education, it is important to understand the mechanisms by which parenting factors have their effect on involvement. Numerous parent and family characteristics have previously been identified that contribute to family involvement. Previous research has investigated the influence of parental education, number of children living in the home, child gender (Manz, Fantuzzo, \& Power, 2004), single-parent status (Arnold, Zeljo, Doctoroff, \& Ortiz, 2008; Manz et al., 2004), and cultural and racial variations (Wong \& Hughes, 2006) on family involvement. 
In addition to the demographic, or "social position" variables, research has identified factors that might account for the process through which parents choose to become involved. One model of the family involvement process has been articulated by Hoover- Dempsey and Sandler (1995, 1997), and Hoover-Dempsey et al. (2005). According to their model, parental motivational beliefs, or beliefs and perceptions that contribute to a parent's inclination to be involved in their child's education, predict family involvement in their child's learning. The model developed by Hoover-Dempsey and colleagues is grounded in a rich conceptual framework and a strong empirical foundation based on a robust measurement protocol. In addition to parental motivational beliefs articulated in Hoover- Dempsey's model, parenting stress has also been identified as a psychological barrier to family involvement in children's education (Fagan, Bernd, \& Whiteman, 2007; Halme, Tarkka, Nummi, \& Åstedt-Kurki, 2006; Waanders, Mendez, \& Downer, 2007) and is a risk factor for children with disruptive behaviors (Pesonen et al., 2008; Räikkönen et al., 2006).

The conceptual model for this study (presented in Figure 1) illustrates a mechanism by which parents' stress and motivational beliefs might be related to family involvement among parents whose children exhibit disruptive behaviors. Stress associated with parenting a child with disruptive behaviors may negatively affect a parent's perceived role and efficacy, which in turn may affect the manifestation of family involvement activities. In contrast, parents with less stress may be more likely to feel confident and competent about their role and ability to interact with their child and school professionals, and therefore, more likely to demonstrate behaviors at home and school to promote their children's learning.

The conceptual model presented for this study builds on previous findings in several ways. First, the effect of parenting stress and motivational beliefs has been studied in isolation without consideration of their interaction and the pathways through which they influence

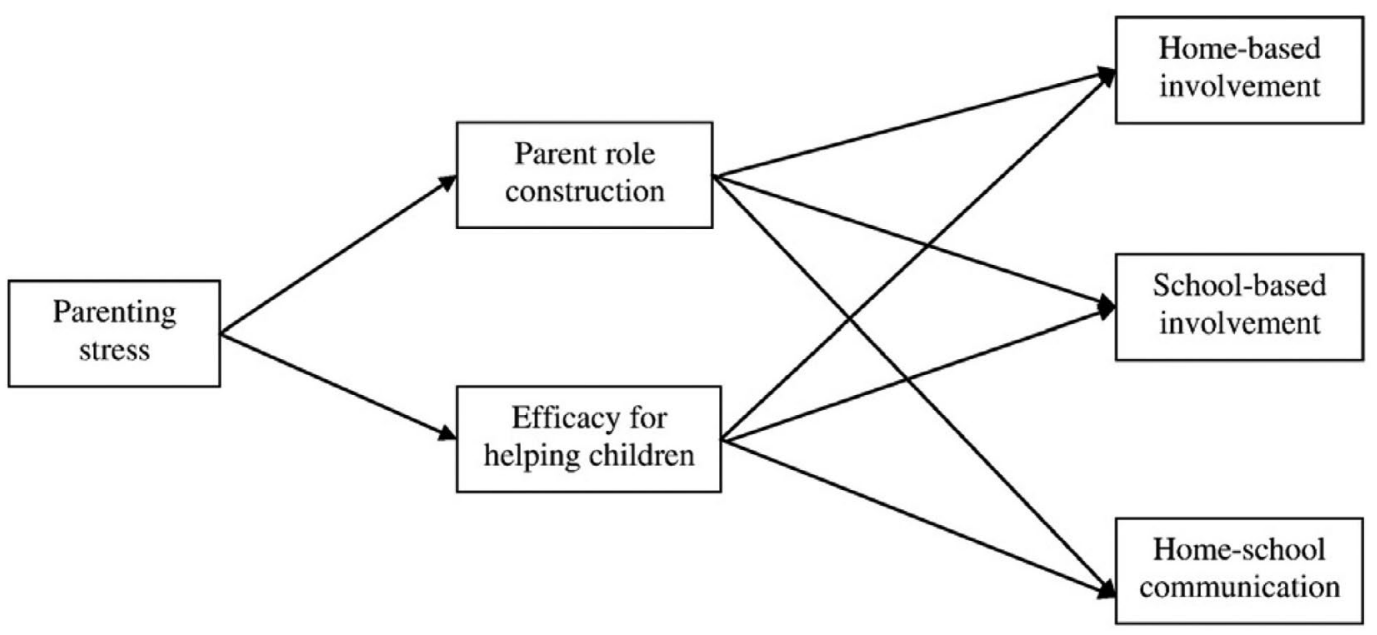

Figure 1. Conceptual model of the mediational role of parental motivational beliefs on the relation between parenting stress and family involvement. 
family involvement. This study will examine how parenting stress might impede family involvement through its negative effect on parents' motivational beliefs. Second, despite the extensive research based on Hoover-Dempsey's model of family involvement, no investigations have examined its relationship to parents of children with disruptive behaviors. Given the potential significance of parenting stress among this population, we expand HooverDempsey's model by examining the impact of parenting stress on parental motivational beliefs and family involvement. Finally, given the malleable nature of parenting stress and motivational beliefs, findings will provide a more thorough understanding for points for intervention to support involvement for families of children with disruptive behavior.

\section{Model constructs}

\subsection{Family involvement}

For this study, family involvement is conceptualized along three dimensions: homebased involvement, school-based involvement, and home-school communication (Epstein, 1995; Fantuzzo et al., 2000). Home-based involvement includes educational activities in which family members actively participate in support of a child's learning at home (Fantuzzo et al., 2000; Hoover-Dempsey \& Sandler, 1997). Examples of such activities include helping with homework and creating a space for learning activities. School-based involvement activities include parents' active participation in educational activities typically undertaken at school, such as volunteering in the classroom or assisting on class field trips (Fantuzzo et al., 2000; Hoover-Dempsey \& Sandler, 1997). Lastly, home- school communication includes interpersonal interactions and connections between family members and teachers, such as attending parent-teacher conferences (Fantuzzo et al., 2000).

\subsection{Parenting stress}

Parenting stress is frequently defined as the negative strain related to the self, the child, and the parent-child interaction in the context of parenthood (Abidin, 1995). Daily stressors associated with parenting serve as a barrier to frequent and regular involvement, engagement, and availability with children and their learning (Fagan et al., 2007; Halme et al., 2006). For example, perceived parenting stress related to financial hardship is linked to reduced family involvement in children's education (Waanders et al., 2007). Similarly, difficult context, defined as stressful life events minus family resources, is related to mothers' involvement (Grolnick, Benjet, Kurowski, \& Apostoleris, 1997). However, mechanisms by which parenting stress has its effect on family involvement and the degree to which certain parenting beliefs influence their involvement have not been studied.

Increased levels of parenting stress are related to adverse child outcomes. Elevated parenting stress is related to poor family adjustment and higher levels of child behavior problems, including lower social competence, higher internalizing and externalizing behaviors, and lower oral language scores (Anthony et al., 2005; Farver, Xu, Eppe, \& Lonigan, 2006; Hart \& Kelley, 2006; McGlone, Santos, Kazama, Fong, \& Mueller, 2002). Parenting stress 
is particularly problematic among families of children with disruptive behaviors. Children with disruptive behaviors have parents who report high levels of parenting stress (Hart \& Kelley, 2006; McGlone et al., 2002; Spratt, Saylor, \& Macias, 2007), and elevated levels of stress have been reported for parents of children with various disabilities, such as autism spectrum disorders (Davis \& Carter, 2008), fragile X syndrome (von Gontard et al., 2002), attention deficit hyperactivity disorder, developmental disabilities (Gupta, 2007), and intellectual disabilities (Baxter, Cummins, \& Yiolitis, 2000; Stores, Stores, Fellows, \& Buckley, 1998). Although parenting stress and child behaviors are likely to mutually influence one another in a reciprocal manner, the effect of parenting stress on difficult child characteristics, such as non-compliance, aggressive, or antisocial behaviors, appears greater than the effect of child behaviors on parenting stress (Pesonen et al., 2008). Therefore, parenting stress has been identified as a risk factor for children with disruptive behaviors (Pesonen et al., 2008; Räikkönen et al., 2006). Elevated parental stress may consume a parent's time and emotional energy, thereby reducing involvement in their child's education (Fagan et al., 2007; Halme et al., 2006) and impeding the potentially positive effects of family involvement. This pattern might be particularly true to parents of children with disruptive behaviors given the demands those children place on their parents.

\subsection{Parental motivational beliefs}

According to seminal work by Hoover-Dempsey and Sandler $(1995,1997)$ and HooverDempsey et al. (2005), parental motivational beliefs include parent role construction and parent efficacy for helping children succeed in school. These parental motivational beliefs have been shown to be related to parents' involvement in their child's education (HooverDempsey \& Sandler, 1995, 1997).

\subsubsection{Parent role construction}

Parent role construction is defined as parents' beliefs about activities they may engage in related to their child's education (Hoover-Dempsey \& Sandler, 1995, 1997; Hoover-Dempsey, Wilkins, O'Conner, \& Sandler, 2004; Walker, Wilkins, Dallaire, Sandler, \& Hoover-Dempsey, 2005). For example, parents have different beliefs regarding the responsibilities they have for activities in children's education such as volunteering at school, helping their children with homework, and communicating with their children's teachers regularly. Parent role construction is positively related to family involvement in education at home and school (Deslandes \& Bertrand, 2005; Hoover-Dempsey et al., 2001; Hoover-Dempsey et al., 2005; Sheldon, 2002) and functions as a motivator of family involvement because it helps parents envision their roles and responsibilities related to multiple child educational activities (Hoover-Dempsey \& Sandler, 1997).

\subsubsection{Parent efficacy}

Parent efficacy is defined as the beliefs parents have about their ability to be successful as parents and positively influence their children's behavior and development (Coleman \& Karraker, 2000; Hess, Teti, \& Hussey-Gardner, 2004). Parental efficacy predicts the behaviors parents will exhibit, how they will act with the skills and personal knowledge they possess, 
what activities they will pursue, how much effort they will expend in activities, and how long they will persist in the face of obstacles or aversive experiences (Bandura, 1994). In general, parents who are not efficacious tend to not pursue tasks they feel are beyond their abilities; rather, a parent must believe that he or she possesses the beliefs, capabilities, and actions to be successful (de Montigny \& Lacharite, 2005).

Parent efficacy with regard to a child's education includes the degree to which parents believe they can exert a positive impact on their children's learning (Hoover-Dempsey \& Sandler, 1997). Parent efficacy for helping their children succeed in school has been shown to predict home- and school-based involvement (Green, Walker, Hoover-Dempsey, \& Sandler, 2007; Walker et al., 2005), indicating that parents are more likely to be involved if they have the belief that their actions will improve learning and academic performance (Green et al., 2007; Grolnick et al., 1997; Hoover-Dempsey, Bassler, \& Brissie, 1992; Stevenson, Chen, \& Uttal, 1990). In contrast, parents who view themselves as less able to effectively contribute to their child's education are more likely to refrain from participating in such activities. Parent efficacy has also been found to partially mediate the effect of children's difficult temperament and family stress on mothers' reports of family involvement in home learning activities (Machida, Taylor, \& Kim, 2002). That is, family stress may indirectly and negatively influence family involvement through lowered parent efficacy. However, additional research is necessary to determine the nature of the relation between parenting stress and parental motivational variables for families of children with disruptive behaviors.

\section{Purpose and research question}

Children with disruptive behaviors are at risk for a number of adverse outcomes across academic, behavioral, and social-emotional domains. Whereas family involvement is a critical component for children's positive educational outcomes, limited research has investigated parents' psychological factors that contribute to family involvement among children with disruptive behaviors. The current study focuses on parents' affective factors (i.e., stress) and motivational factors (i.e., role construction and efficacy) that may relate to family involvement for children with behavioral concerns. Specifically, parenting stress might be significant for families of children with disruptive behaviors, which may interfere with family involvement.

In this study, we will empirically examine the conceptual model presented in Figure 1. Building on and expanding the model presented by Hoover-Dempsey and Sandler (1995, 1997) and Hoover-Dempsey et al. (2005), this study aims to investigate the role of parental motivational beliefs (i.e., role construction and efficacy) as a potential mechanism that influences the effects of parenting stress on involvement in their child's education. Notably, these relationships are explored for families of children who present disruptive behaviors in their early years of formal schooling (i.e., grades kindergarten through 3).

We investigated the following research question in this study: Is the relation between parenting stress and family involvement mediated by parental motivational beliefs (i.e., parent role construction and parent efficacy)? Based on initial research on parenting stress and family involvement, it is hypothesized that parental motivational beliefs (i.e., parent role construction and parent efficacy) will mediate the negative relation between parenting stress and family involvement in families of children with disruptive behaviors. 


\section{Methods}

\subsection{Participants and setting}

Participants were 207 parents and children in kindergarten through 3rd grades in 82 classrooms in 21 public and parochial schools in a moderately-sized Midwestern city and surrounding communities. Participating parents' ages ranged from 23 to 58 , with a mean age of 34.5 years. Eighty-nine percent of participating parents were female, and $11 \%$ were male. Eighty-six percent of participating parents characterized themselves as White, $5 \%$ as African American, 4\% as Latino, 2\% as American Indian/Alaska Native, and 3\% as biracial. Fiftysix percent of participating parents reported acquiring less than a college degree. Fifty-eight percent of participating parents indicated that two adults were living in the home, $25 \%$ indicated that one adult was living in the home, and 17\% indicated that more than two adults were living in the home. The U.S. Census Bureau (2000) description of the city in which the majority of the sample was drawn reported a population that was $89 \%$ White, $4 \%$ Latino, $3 \%$ African American, 3\%, Asian, $1 \%$ American Indian/Alaska Native, and 2\% two or more races. The Census for 2000 reported that the city's population was $50 \%$ female, $50 \%$ male, and $67 \%$ of the population had attained less than a Bachelor's degree. Therefore, the parent sample was similar to the city in which the study was conducted; however, this study's parent sample included primarily mothers.

Participating children's ages ranged from 5 to 9 years, with a mean age of 6.5 years. Seventy-seven percent of students were boys, and $23 \%$ were girls. Seventy-five percent of participating parents characterized their children as White, 10\% as African American, 4\% as Latino, $1 \%$ as American Indian/Alaska Native, and 10\% as bi-racial. Fifty percent of participating children were eligible to receive free or reduced lunch at school, and $38 \%$ met criteria for living at the $150 \%$ poverty level (i.e., annual incomes 1.5 times the poverty threshold). The criterion for $150 \%$ poverty level was used as the low-income measure in this study due to indications that federal poverty levels are too low to adequately represent the number of individuals who are living in financial hardship (Edin \& Lein, 1997). Ninety-four percent of the children attended public schools, and 6\% attended parochial schools. The local public school district reported demographic information that aligns with the sample used in this study, including children in grades $\mathrm{K}-3$ from the 2005-2006 school year, the initial year of data collection for this study. The public school district reported $38 \%$ of the student population participated in the free or reduced lunch program, $51 \%$ were boys, and $49 \%$ were girls. The public school district population was reported to be $77 \%$ White, $10 \%$ African American, 7\% Hispanic/Latino American, 4\% Asian American, and 2\% Native American (Lincoln Public Schools, 2005). Therefore, the child sample was similar to the city in which the study was conducted; however, this study included a sample with somewhat lower SES and a majority of boys.

\subsection{Recruitment and procedures}

This study is part of a large randomized trial assessing the efficacy of conjoint behavioral consultation (CBC; Sheridan \& Kratochwill, 2008) on improving disruptive behaviors in children from kindergarten to 3rd grade. Because the purpose of the present study was to 
examine relations between parenting variables among parents of children with disruptive behaviors, not to test intervention effects, analyses in this investigation included data from all participants, regardless of condition (i.e., CBC experimental or control). Recruitment of students followed a multi-gate screening procedure. The first gate involved teacher nomination and ratings. Teachers were asked to rank the top 10 students with externalizing behaviors (e.g., non-compliance and aggression) within their individual classrooms and to complete the Systematic Screening for Behavior Disorders (SSBD; Walker \& Severson, 1990) rating scale for the top 5 ranked children. To gather additional information for these five children pertaining to behavioral problems related to the larger clinical trials, teachers also completed a researcher-developed checklist assessing frequency and severity of externalizing behaviors as well as the need for additional intervention. Severity and frequency of externalizing behaviors were rated by teachers on a 9-point Likert-type scale. Anchors on the severity scale were 1 (very mild), 3 (somewhat mild), 5 (moderate), 7 (somewhat severe), and 9 (very severe). Severity of student behavior for children participating in this study ranged from 3 to 9, with a mean severity rating of 6.64. Anchors on the frequency scale were 1 (very infrequent), 3 (somewhat infrequent), 5 (moderate), 7 (somewhat frequent), and 9 (very frequent). Frequency of student behavior ranged from 3 to 9 , with a mean frequency rating of 6.84. Teachers also rated perceived need of intervention on a 5-point Likert-type scale, (i.e., the need for additional intervention). Anchors for this scale included 1 (no need), 3 (moderate need), and 5 (significant need). The perceived need of intervention ranged from 2 to 5 , with a mean rating of 4.04. The internal consistency for the three-item (severity, frequency, and need) screening scale was $\alpha=.84$. A composite score based on the three items was negatively correlated with SSBD adaptive skills $(r=-.56, p<.01)$ and positively correlated with SSBD maladaptive skills $(r=.41, p<.01)$.

Students met criteria to be included in the study when they (a) scored in the elevated or extremely elevated risk categories on the SSBD, and/or (b) were reported to exhibit externalizing behaviors that interfered with learning at a moderate to extremely severe level, occurred at a moderate to extremely frequent level, or demonstrated moderate to significant need for additional services (Glover et al., 2005). Specifically, teachers initially nominated 383 students for participation. Of those 383 students, 274 were eligible to participate in the study (i.e., they qualified for participation based on screening criteria). Once students were identified, two to three students with the highest levels of behavior severity were selected per classroom. Their parents were contacted, informed of the study, and invited to participate. A total of 207 parents and students provided consent for participation. However, it should be noted that 17 cases out of 207 had missing data on all study variables. These cases were not included in the analyses, reducing the sample size to 190 for analyses.

\subsection{Predictor, outcome, and mediator variables}

The predictor variable in this investigation was self-reported levels of parenting stress. The criterion variable was parents' self-report of their involvement in their child's education at home and school. Mediator variables were parents' motivational beliefs with regard to their perceived role in and efficacy for helping their child succeed in school. 


\subsection{Measures}

\subsubsection{Parenting Stress Index-Third Edition Short Form}

The Parenting Stress Index-Third Edition Short Form (PSI-SF; Abidin, 1995) is a self-report scale that consists of three subscales: parental distress (e.g., "I feel trapped by my responsibilities as a parent"), difficult child characteristics (e.g., "My child makes more demands on me than most children") and dysfunctional parent-child interaction (e.g., "My child is not able to do as much as I expected"). These three scales compose a total stress index. Its 36 items are rated on a 5-point Likert-type scale ranging from o (strongly disagree) to 4 (strongly agree). Based on guidelines in the PSI-SF scoring manual, a sum of the subscales is created to derive the Total Stress Index. This index was used in this study to quantify parent stress; Cronbach's alpha coefficient for this study was .89. Construct and predictive validity evidence supporting the full-length PSI and PSI-SF scores has been produced across studies including a range of child and family samples (e.g., Abidin, 1995; Haskett, Ahern, Ward, \& Allaire, 2006).

\subsubsection{Family Involvement Questionnaire-Elementary Version}

The Family Involvement Questionnaire-Elementary Version (FIQ-E; Manz et al., 2004) is a multidimensional self-report scale measuring family involvement. Its 46 items are rated on a 4-point Likert-type scale ranging from 1 (rarely occurs) to 4 (always occurs). Factor-analytic research has revealed three distinct dimensions: School-Based Involvement, HomeBased Involvement, and Home-School Communication. The FIQ has been normed with a national sample and $T$-scores $(M=50, \mathrm{SD}=10)$ are derived for each dimension (Perry, Fantuzzo $\&$ Munis, 2002). Cronbach's alpha coefficients for our sample were .82, .86, and .85 for the School-Based, Home-School Communication, and Home-Based Involvement dimensions, respectively. Evidence of construct validity for the FIQ-E has been reported (Manz et al., 2004).

\subsubsection{Parent Role Construction scale}

The Parent Role Construction scale (PRCS; Hoover-Dempsey \& Sandler, 1997; Walker et al., 2005) is a self-report scale that assesses parent beliefs about what they should do and how active they should be in relation to their child's education (e.g., "I believe it is my responsibility to volunteer at the school"). Its 10 items are rated on a 6-point Likert-type rating scale ranging from 1 (disagree very strongly) to 6 (agree very strongly). The PRCS has been used in various studies investigating how parents describe their role (e.g., HooverDempsey, Wilkins, O’Connor, \& Sandler, 2004). These studies have reported acceptable reliability estimates $(\alpha=.80-.83)$. Cronbach's alpha coefficient for this study was 79 .

\subsubsection{Parent Efficacy for Helping Children Succeed in School scale}

The Parent Efficacy for Helping Children Succeed in School scale (PEHCSS; HooverDempsey \& Sandler, 1997; Walker et al., 2005) measures parents' beliefs about their ability to positively affect their child's educational outcomes through their involvement (e.g., "I know how to help my child do well in school"). Its 12 items are rated on a 7-point Likerttype scale ranging from 1 (disagree very strongly) to 7 (agree very strongly). The PEHCSS relies on considerable empirical and theoretical support and a previously reported alpha 
coefficient of.80 (Hoover-Dempsey et al., 1992; Walker et al., 2005). Cronbach's alpha coefficient for this study was .82 .

\subsection{Analysis}

The research question in the current study asks whether parental motivational beliefs mediate the relation between parenting stress and family involvement at home and school. Path analysis was conducted to address the question, using MPLUS 4.2 (Muthén \& Muthén, 1998, 2006). We followed advanced guidelines for testing mediation that contrasts with the traditional approach in several ways (Frazier, Tix, \& Barron, 2004; Mallinckrodt, Abraham, Wei, \& Russell, 2006; Shrout \& Bolger, 2002). Specifically, the traditional approach to testing mediation (Baron \& Kenny, 1986) involves a statistical test designed for variables that follow standard normal distribution, a $z$-test. However, because mediation involves the product of two effects (i.e., the effect of the predictor on the mediator and the effect of the mediator on the outcome), the sampling distribution of the product of two regression coefficients deviates from a normal distribution. Thus, applying a normal theory approach (Mallinckrodt et al., 2006) that compares the mediation point estimate to a normal distribution can reduce the statistical power to detect mediation and may bias results.

Shrout and Bolger (2002) suggested an alternative approach to testing mediation, particularly useful when the sample size, mediation effects, or both are small, that involves a bootstrap procedure for correcting the standard errors of indirect (i.e., mediation) effects. This approach increases the statistical power to detect mediation effects and does not assume a normal sampling distribution. They also recommended reporting confidence intervals of mediation effects such that if the 95\% confidence interval does not include o (zero), then the mediation is statistically significant at the .05 level. Shrout and Bolger's approach has proven to be powerful in testing mediation (MacKinnon, Lockwood, \& Williams, 2004; Mallinckrodt et al., 2006). Specifically, a bootstrap procedure involves constructing a number of resamples based on the observed data set. The underlying assumption is that the original sample is drawn from the population; thus, a number of resamples drawn by the observed sample should represent possible samples if many samples were drawn from the population. The obtained distribution of the product of the regression coefficients is the sampling distribution for the indirect effect. In the current study, 10,00o bootstrap samples were created from the original data set with replacement based on Mallinckrodt et al. (2006) recommendations.

\section{Results}

First, given that two to three children and their parents were drawn from the same classroom, we examined whether or not a nesting structure needs to be taken into account in the analyses. Specifically, we examined intraclass correlations (ICC) and design effect estimates associated with the outcome variables (see Peugh, 2010). The ICCs were .05, o, and o for home-based involvement, school-based involvement, and home-school communication, respectively. In other words, a small amount of variance (i.e., 5\%) in home-based involvement is attributed to between classrooms, whereas no variance in school-based involvement 
and home-school communication is attributed to between classrooms. Conceptually, parental educational involvement activities in the home setting are disconnected to shared classrooms of the parents' children. Further, the design effect estimate for home-based involvement was 1.07, which does not suggest a strong need for a multi-level modeling technique. Taken together, the analyses below were conducted at a single level as if parents were independent from one another.

The means, standard deviations, and correlations among study variables are presented in Table 1. Correlation analyses indicated significant but small relations between parenting stress and home-based family involvement $(r=-.20, p<.05)$ and school-based family involvement $(r=-.20, p<.05)$. The relation between parenting stress and home-school communication was not significant $(r=-.04, p \geq .05$ ). Parenting stress was negatively and significantly associated with parent role construction $(r=-.30, p<.01)$ and with parent efficacy for helping children succeed in school $(r=-.59, p<.01)$. However, parent role construction and parent efficacy were positively and significantly associated with the three aspects of family involvement. Moderate and positive correlations were found between parent role construction and parent efficacy $(r=.40, p<.05)$. Finally, small to moderate positive correlations, ranging from $r=.22$ to .40 , were found among the three aspects of family involvement.

Path analysis was used to test whether parental motivational beliefs mediate the relation between parenting stress and the three aspects of family involvement (see Figure 2). The model fit of the path model was evaluated using chi-square statistics, the comparative fit index (CFI), the root mean-squared error of approximation (RMSEA), and the standardized root mean square residual (SRMR). According to Hu and Bentler (1999) recommendation, CFI values greater than .95, RMSEA less than .06, and SRMR less than .08 indicate an excellent fit. Fit indices indicated that the proposed model fits the data very well: $\chi^{2}(3)$ $=3.00, p=.39, \mathrm{CFI}=1.00, \mathrm{RMSEA}=.00$, and $\mathrm{SRMR}=.02$.

The path coefficients presented in Figure 2 are standardized, and the significance tests are associated with the raw regression weights. As shown in Figure 2, parenting stress was a statistically significant predictor of parent role construction $(\beta=-.22, p<.05)$ and parent efficacy $(\beta=-.55, p<.05)$. Parent role construction was a significant predictor of homebased involvement $(\beta=.21, p<.05)$, school-based involvement $(\beta=.30, p<.05)$, and home- school communication $(\beta=.23, p<.05)$. Parent efficacy was a significant predictor of home-based involvement $(\beta=.32, p<.05)$ but not of school-based involvement

Table 1. Intercorrelations, means, and standard deviations for study variables.

\begin{tabular}{|c|c|c|c|c|c|c|}
\hline Variable & 1 & 2 & 3 & 4 & 5 & 6 \\
\hline 1. Parenting stress & - & & & & & \\
\hline 2. Parent role construction & $-.30^{* *}$ & - & & & & \\
\hline 3. Parent efficacy for helping children & $-.59 * *$ & $.40^{* *}$ & - & & & \\
\hline 4. Home-based involvement & $-.20^{*}$ & $.36^{* *}$ & $.37^{* *}$ & - & & \\
\hline 5. School-based involvement & $-.20^{*}$ & $.30^{* *}$ & $.26 * *$ & $.22^{*}$ & - & \\
\hline 6. Home-school communication & -.04 & $.31^{* *}$ & $.21^{*}$ & $.40^{* * *}$ & $.30^{* *}$ & - \\
\hline Mean & 76.73 & 5.21 & 4.56 & 60.03 & 46.86 & 58.48 \\
\hline Standard deviation & 16.32 & .48 & .72 & 9.29 & 8.25 & 11.88 \\
\hline
\end{tabular}

${ }^{*} p<.05 ;{ }^{* *} p<.01$ 


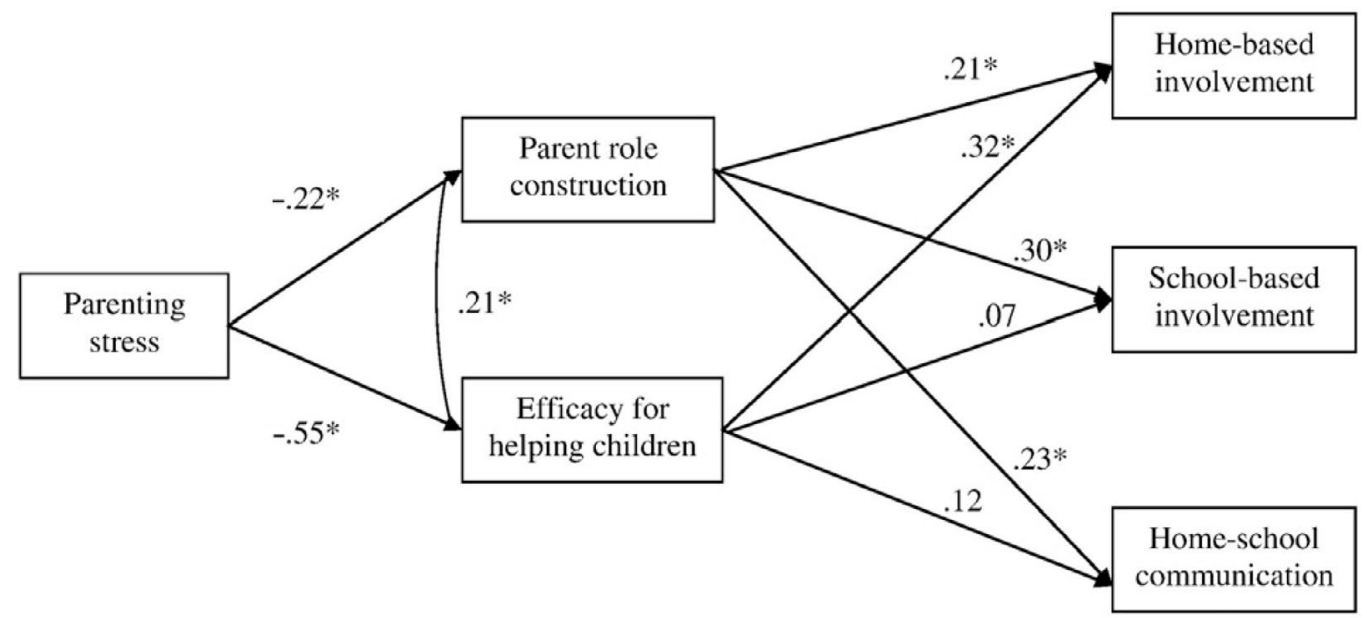

Figure 2. Path model of the effect of parenting stress on family involvement mediated through parent motivational beliefs. ${ }^{*} p<.05$

( $\beta=.07, p \geq .05$ ) or of home-school communication $(\beta=.12, p \geq .05)$. Also, we allowed the error variances for parent role construction and parent efficacy to covary given that they reflect a common theoretical construct of parents' motivational beliefs (Walker et al., 2005). The correlation between the errors of parent role construction and parent efficacy was significant $(r=.21, p<.05)$. In fact, a failure to allow them to covary resulted in unacceptable model fit. Overall, parenting stress explained approximately $5 \%$ of the variance in parent role construction and 30\% of the variance in parent efficacy. Parent role construction and parent efficacy together explained approximately $19 \%$ of the variance in home-based involvement, $11 \%$ of the variance in school-based involvement, and $9 \%$ of the variance in home-school communication.

Subsequently, mediation of parent role construction and parent efficacy on the relation between parenting stress and family involvement were tested by examining a total of six indirect effects. It should be noted that we conducted a mediation analysis despite the fact that the direct relation between parenting stress and home-school communication was not significant. It is now recognized that a direct, significant relation between a predictor and

Table 2. Bootstrap analysis of indirect effects and confidence intervals.

\begin{tabular}{llllll}
\hline $\begin{array}{l}\text { Independent } \\
\text { variable }\end{array}$ & $\begin{array}{l}\text { Mediator } \\
\text { variable }\end{array}$ & $\begin{array}{l}\text { Dependent } \\
\text { variable }\end{array}$ & Estimates & $\begin{array}{l}\text { Standard } \\
\text { error }\end{array}$ & $\begin{array}{l}\text { 95\% CI (lower bound, } \\
\text { upper bound) }\end{array}$ \\
\hline $\mathrm{PSI} \rightarrow$ & $\mathrm{PRC} \rightarrow$ & HI & -.03 & .01 & $(-.06,-.01)$ \\
$\mathrm{PSI} \rightarrow$ & $\mathrm{EHC} \rightarrow$ & HI & -.10 & .03 & $(-.16,-.05)$ \\
$\mathrm{PSI} \rightarrow$ & $\mathrm{PRC} \rightarrow$ & SI & -.03 & .02 & $(-.07,-.01)$ \\
$\mathrm{PSI} \rightarrow$ & $\mathrm{EHC} \rightarrow$ & SI & -.02 & .02 & $(-.06, .02)$ \\
$\mathrm{PSI} \rightarrow$ & $\mathrm{PRC} \rightarrow$ & HS & -.04 & .02 & $(-.08,-.01)$ \\
$\mathrm{PSI} \rightarrow$ & $\mathrm{EHC} \rightarrow$ & HS & -.05 & .03 & $(-.12, .01)$ \\
\hline
\end{tabular}

PSI = Parenting Stress Index, PRC = Parent Role Construction, EHC = Efficacy for Helping Children Succeed in School, HI = home-based involvement, $\mathrm{SI}=$ school involvement, HS = home-school communication, $\mathrm{CI}=$ confidence intervals. 
outcome variable is not a necessary prerequisite for testing mediation. Examples include when there are multiple mediators and when the predictor variable precedes the outcome variable far in advance (Frazier et al., 2004; Kenny, Kashy, \& Bolger, 1998; Shrout \& Bolger, 2002). The direct relation between parenting stress and home-school communication among parents of children with disruptive behavior problems has not been well established in the literature, and many mediating variables may be relevant in addition to those of primary concern in the present investigation (i.e., parents' motivational beliefs), so mediation analyses were conducted for this relation.

The parameter estimate of the indirect effect (i.e., the product of the path leading to the mediator and the path leading from the mediator to the outcome), standard error, and confidence intervals is presented in Table 2. To recap, the indirect effect is significant when the confidence interval does not include zero. As seen in Table 2, the indirect effects of parenting stress on family involvement through parent role construction were significant for all three aspects of family involvement. The indirect effects of parenting stress on family involvement through parent efficacy were significant for home-based involvement but not for school-based involvement or for home-school communication. In other words, parent role construction mediated the relation between parenting stress and the three aspects of family involvement, whereas parent efficacy mediated the relation between parenting stress and home-based involvement only.

\section{Discussion}

The purpose of this study was to investigate the role of parental motivational beliefs (i.e., role construction and efficacy) as a potential mechanism by which parenting stress impacts family involvement for families of children with disruptive behaviors. Results indicated that parent role construction mediated the relation between parenting stress and the three dimensions of family involvement, whereas parent efficacy mediated the relation between parenting stress and home-based involvement only.

Parents' reported stress levels were directly negatively related to their beliefs about their roles in their child's learning and to their perception of their efficacy at influencing learning and educational outcomes. Furthermore, consistent with Hoover-Dempsey and Sandler $(1995,1997)$, we found significant positive relations between role construction and efficacy with home-based involvement, school-based involvement, and home-school communication. Significant indirect effects of parenting stress on family involvement were found through the effect on parent role construction. Thus, we can expect that parents reporting stress may experience negative beliefs vis á vis their own role and ability to support their child's education, which may thereby negatively influence their actual involvement. The effect of stress on family involvement is lessened as parents demonstrate increased beliefs about their role in supporting their child's learning. Interventions requiring family involvement or participation (e.g., conjoint behavioral consultation and parent training) among parents experiencing stress may fail if practitioners neglect to understand the important influence of parental cognitions about their role in education-related activities. Efforts to promote positive parental role construction may be an indicated component of family involvement interventions, particularly for families experiencing stress. 
Significant indirect effects of parenting stress on family involvement through parent efficacy were found for home-based involvement. In other words, stressed parents of children with disruptive behaviors may experience negative beliefs regarding their own efficacy, which may thereby negatively influence their actual involvement in educational activities at home. The effect of stress on family involvement at home may be lessened as parents demonstrate increased self-efficacy regarding their ability to help their child in educational pursuits. However, the indirect effects of parenting stress on family involvement through parent efficacy were not significant for school-based involvement or home-school communication. Parents who are stressed and question their parenting efficacy may be unaware of the benefits of school-based involvement or participation in school programs (e.g., learning new skills or strategies and partnering to meet goals they share for their child). Additional research is necessary to better understand the unique role of parent efficacy on the relationship between parenting stress and involvement across settings (i.e., home and school)particularly for parents of children with disruptive behaviors who may benefit from various forms of involvement.

The findings of the present study are significant for several reasons. Researchers have long known about the importance of family involvement and the influence of stress on parent engagement and involvement with their child and their child's education (Fagan et al., 2007; Halme et al., 2006; Waanders et al., 2007). However, this study represents the first to examine a conceptual model articulating the mechanism for the relation between parental stress and family involvement. Specifically, this study supports and expands on previous literature investigating these constructs. For example, we know from this and other research (Hoover-Dempsey \& Sandler, 1995, 1997) about the important predictive nature of parents' motivational beliefs on their involvement in education. This study expands on previous findings to elucidate the significant negative effect of parenting stress on parent motivational beliefs. Furthermore, the demonstration of parental motivational beliefs as mediators of the relation between parenting stress and family involvement adds to the literature by explaining a process predicting family involvement. The study also expands the results of similar work by Machida et al. (2002) who found that parent efficacy mediated the effect of family stress on mothers' reports of family involvement in home learning activities for a population of children without disruptive behaviors.

\subsection{Limitations}

Despite the important contributions of this study, certain limitations are evident that warrant caution when interpreting the findings. The limitations include concerns with a targeted sample, limited measurement, and narrow understanding of family context. First, this study was conducted as part of a larger randomized trial investigating the efficacy of conjoint behavioral consultation (Sheridan \& Kratochwill, 2008) for reducing disruptive behaviors in students who met stringent behavioral criteria. Thus, it is likely that child characteristics such as certain behavioral sequelae, topographical features of disruptive behaviors, or child temperament create unique conditions influencing family stress, motivational beliefs, and involvement, and the relations among them. The pathways by which stress and motivational beliefs relate to involvement may be specific or responsive to the behavioral issues 
present in these select families; therefore, findings of this study cannot be generalized to parents of children with other presenting concerns, such as those with internalizing disorders, health problems, or cognitive delays. Further investigations are needed to determine whether child characteristics pose unique challenges in the process of family involvement.

Second, as with any study, it is not possible to measure any variable completely, and interpretation of the constructs of interest is limited to the manner in which they are assessed. In the present study, parenting stress, motivational beliefs, and family involvement were measured within a narrow framework, using self-report methods from one source only (i.e., the parent). In the case of parenting stress, the PSI-SF was used to measure the overall level of stress experienced by parents in that role. Thus, it did not take into account other sources of stress such as financial strain, mental health issues, or physical or health-related problems. Future studies should investigate the role of family stress across multiple sources of stress.

Measurement of family involvement at home and school was also obtained from only self-report scales. It is possible that parents' responses may have been influenced by a desire to appear involved in their child's educational life more than they actually are and that their perception of involvement does not match the perceptions held by others (e.g., teachers and students). Compared to assessments of cognitions (i.e., beliefs and motivation), the family involvement variable lends itself to objective measurement. Observational measures of engagement during meetings or conferences, attendance at school events, and teacher reports of participation or parent-teacher relationships are possible alternatives to self-report methods in need of psychometric scrutiny (Mullaney et al., 2009).

Furthermore, the benefits of parent participation in their child's education are now understood to be a function of factors more broad than "involvement" alone. Constructs such as parent engagement, parent-teacher relationships, and family-school partnerships are more inclusive of the many facets involved in the interface of families with educational experiences. Thus, the manner in which the outcome variable was measured in this study may limit the conclusions that can be drawn. Finally, it is important to recognize that the variables of interest in this study were measured using parents as respondents and that the majority (i.e., 89\%) of the parents were mothers. Research using multi-method and multisource approaches to investigate important relations among these family variables is necessary.

Finally, the present research investigated the degree to which parent motivational beliefs mediate the effect of stress on their involvement in education. A number of potentially relevant parent and child variables were not included in the analyses, thereby limiting understanding of the family context within which the findings can be interpreted. A range of contextual variables interact to influence parents' decisions about involvement, including the range, type, and number of social supports available to parents; familial socioeconomic status; cultural match; parental education levels; and maternal depression (Kohl, Lengua, McMahon, \& the Conduct Problems Prevention Research Group, 2000). Similarly, child variables such as nature and severity of externalizing behavioral problems may also play a moderating role in the relation between parent stress and family involvement. These and other demographic, intrapersonal, and interpersonal variables may moderate the relations studied here, such that the findings hold only under certain family life contexts or conditions. A moderated mediation model may be useful to explore important parent, child and family factors that influence the relations among variables leading to involvement in education at home and school. 


\subsection{Future research}

Understanding the pathways between parental stress, beliefs, and involvement helps uncover meaningful relations for future investigations. Our study investigated parents of students with disruptive behaviors, as identified by their teachers. Selection of study participants by virtue of teacher report of child behavior may have influenced a select composition of parents. For example, they reported generally average levels of parenting stress, an average to high degree of motivational beliefs as a parent (i.e., parent role construction and efficacy), and generally average to above average involvement in children's education at home and school (albeit more involved at home than at school with average $T$-scores for home and school involvement equaling 60 and 47, respectively). Similarly, there were some parents who failed to consent to participation despite their child's fit with the inclusionary criteria. Patterns of involvement for parents who refer their own children for specialized services, who reject invitations to participate in support programs, or whose children present with concerns other than externalizing behavior problems may vary from what was found with the present sample. Future studies might examine whether differences exist in family involvement (a) between parents of children with and without disruptive behavior problems or (b) between parents who self-identify problems in their children's behaviors and parents whose children are referred by non-family members.

Our study included the reports of parents of children with disruptive behaviors who were primarily boys. Families of boy students report more family involvement activities than families of girl students (Manz et al., 2004). Likely, this finding is due to a higher prevalence of teacher-reported disruptive behavior difficulties for boys (DuPaul et al., 1997; Levy, Hay, Bennett, \& McStephen, 2005), resulting in an increased need for communication in response to behavioral difficulties. However, previous research demonstrated that a stressed or difficult context undermines parental school involvement for boys only (Grolnick et al., 1997). As a result, child gender should be considered in future research investigating family involvement.

Likewise, parents of children from diverse cultural, racial, and economic groups may have different challenges and ideas about family involvement. Low-income parents may be less involved in their children's school activities due to time and job constraints and lack of social support (Evans, 2004). In our sample, slightly over one-third of participating families were living at the $150 \%$ poverty level; however, we did not investigate the effects of socioeconomic status on parents' motivational beliefs or family involvement. Culturally and ethnically diverse families also may be seen as uninvolved by traditional standards. For example, in some cultures families are expected to defer to teachers who are considered educational experts and questioning a teacher may be seen as disrespectful to a teacher's expertise (Lopéz, 2001; Suárez-Orozco \& Suárez-Orozco, 2001). Finally, language differences may pose very pragmatic challenges for traditional forms of family involvement. Factors that may impede family involvement practices for children with diverse socioeconomic, cultural, ethnic, and linguistic backgrounds are in need of investigation. Indeed, future investigations of the proposed conceptual model should include and investigate a diverse range of cultural, racial, and socioeconomic groups. 


\section{References}

Abidin, R. R. (1995). Parenting Stress Index: Professional manual, 3rd ed. Odessa, FL: Psychological Assessment Resources.

Aeby, V. G., Manning, B. H., Thyer, B. A., \& Carpenter-Aeby, T. (1999). Comparing outcomes of an alternative school program offered with and without intensive family involvement. The School Community Journal, 9, 17-32.

Anthony, L. G., Anthony, B. J., Glanville, D. N., Naiman, D. Q., Waanders, C., \& Shaffer, S. (2005). The relationships between parenting stress, parenting behavior and preschoolers' social competence and behavior problems in the classroom. Infant and Child Development, 14, 133-154.

Arnold, D. H., Zeljo, A., Doctoroff, G. L., \& Ortiz, C. (2008). Parent involvement in preschool: Predictors and the relation of involvement to preliteracy development. School Psychology Review, 37, 74-90.

Bandura, A. (1994). Self-efficacy. In V. S. Ramachaudran (Ed.), Encyclopedia of human behavior, Vol. 4 (pp. 71-81). New York: Academic Press.

Barnard, W. M. (2004). Parent involvement in elementary school and educational attainment. Children and Youth Services Review, 26, 39-62.

Baron, R. M., \& Kenny, D. A. (1986). The moderator-mediator variable distinction in social psychological research: Conceptual, strategic, and statistical considerations. Journal of Personality and Social Psychology, 51, 1173-1182.

Baxter, C., Cummins, R. A., \& Yiolitis, L. (2000). Parental stress attributed to family members with and without disability: A longitudinal study. Journal of Intellectual and Developmental Disability, 25, 105-118.

Bub, K. L., McCartney, K., \& Willett, J. B. (2007). Behavior problem trajectories and first-grade cognitive ability and achievement skills: A latent growth curve analysis. Journal of Educational Psychology, 99, 653-670.

Christenson, S. L., \& Sheridan, S. M. (2001). Schools and families: Creating essential connections for learning. New York: Guilford Press.

Coleman, P. K., \& Karraker, K. H. (2000). Parenting self-efficacy among mothers of school-age children: Conceptualization, measurement, and correlates. Family Relations, 49, 13-24.

Comer, J. P., \& Haynes, N. M. (1991). Parent involvement in schools: An ecological approach. The Elementary School Journal, 91, 271-277.

Davis, N. O., \& Carter, A. S. (2008). Parenting stress in mothers and fathers of toddlers with autism spectrum disorders: Associations with child characteristics. Journal of Autism and Developmental Disorders, 38, 1278-1291.

de Montigny, F., \& Lacharite, C. (2005). Perceived parental efficacy: Concept analysis. Journal of Advanced Nursing, 49, 387-396.

Deslandes, R., \& Bertrand, R. (2005). Motivation of parent involvement in secondary-level schooling. Journal of Educational Research, 98, 164-175.

Domina, T. (2005). Leveling the home advantage: Assessing the effectiveness of parental involvement in elementary school. Sociology of Education, 78(3), 233-249.

DuPaul, G., Power, T., Anastopoulos, A., Reid, R., McGoey, K., \& Ikeda, M. (1997). Teacher ratings of attention-deficit/hyperactivity disorder: Factor structure and normative data. Psychological Assessment, 9, 436-444.

Edin, K., \& Lein, L. (1997). Making ends meet. New York: Russell Sage.

Epstein, J. L. (1995). School/family/community partnerships. Phi Delta Kappan, 76, 701-712.

Evans, G. W. (2004). The environment of childhood poverty. American Psychologist, 59, 77-92.

Fagan, J., Bernd, E., \& Whiteman, V. (2007). Adolescent fathers' parenting stress, social support, and involvement with infants. Journal of Research on Adolescence, 17, 1-22.

Fantuzzo, J., Tighe, E., \& Childs, S. (2000). Family Involvement Questionnaire: A multivariate assessment of family participation in early childhood education. Journal of Educational Psychology, 92, 367-376. 
Farver, J. M., Xu, Y., Eppe, S., \& Lonigan, C. J. (2006). Home environments and young Latino children's school readiness. Early Childhood Research Quarterly, 21, 196-212.

Frazier, P. A., Tix, A. P., \& Barron, K. E. (2004). Testing moderator and mediator effects in counseling psychology. Journal of Counseling Psychology, 51, 115-134.

Glover, T., Sheridan, S. M., Garbacz, S. A., \& Witte, A. (2005). Behavior severity, behavior frequency, and need for intervention screening tool. Unpublished scale.

Green, C. L., Walker, J. M. T., Hoover-Dempsey, K. V., \& Sandler, H. M. (2007). Parents' motivations for involvement in children's education: An empirical test of a theoretical model of parental involvement. Journal of Educational Psychology, 99, 532-544.

Grolnick, W. S., Benjet, C., Kurowski, C. O., \& Apostoleris, N. H. (1997). Predictors of parent involvement in children's schooling. Journal of Educational Psychology, 89, 538-548.

Grolnick, W. S., \& Slowiaczek, M. L. (1994). Parents' involvement in children's schooling: A multidimensional conceptualization and motivational model. Child Development, 65, 237-252.

Gupta, V. B. (2007). Comparison of parenting stress in different developmental disabilities. Journal of Developmental and Physical Disabilities, 19, 417-425.

Halme, N., Tarkka, M.-T., Nummi, T., \& Åstedt-Kurki, P. (2006). The effect of parenting stress on fathers' availability and engagement. Child Care in Practice, 12, 13-26.

Hart, M. S., \& Kelley, M. L. (2006). Fathers' and mothers' work and family issues as related to internalizing and externalizing behavior of children attending day dare. Journal of Family Stress, 27, 252-270.

Haskett, M. E., Ahern, L. S., Ward, C. S., \& Allaire, J. C. (2006). Factor structure and validity of the parenting stress index-short form. Journal of Clinical Child and Adolescent Psychology, 35, 302-312.

Hess, C. R., Teti, D. M., \& Hussey-Gardner, B. (2004). Self-efficacy and parenting of high-risk infants: The moderating role of parent knowledge of infant development. Journal of Applied Developmental Psychology, 25, 423-437.

Hoover-Dempsey, K. V., Bassler, O. C., \& Brissie, J. S. (1992). Explorations in parent-school relations. Journal of Educational Research, 85, 287-294.

Hoover-Dempsey, K. V., Battiato, A. C., Walker, J. M. T., Reed, R. P., DeJong, J. M., \& Jones, K. P. (2001). Parental involvement in homework. Educational Psychologist, 36, 195-209.

Hoover-Dempsey, K. V., \& Sandler, H. M. (1995). Parental involvement in children's education: Why does it make a difference? Teachers College Record, 97, 310-331.

Hoover-Dempsey, K. V., \& Sandler, H. M. (1997). Why do parents become involved in their children's education? Review of Educational Research, 67, 3-42.

Hoover-Dempsey, K. V., Walker, J. M. T., Sandler, H. M., Whetsel, D., Green, C. L., Wilkins, A. S., et al. (2005). Why do parents become involved? Research findings and implications. The Elementary School Journal, 106, 105-130.

Hoover-Dempsey, K. V., Wilkins, A. S., O’Connor, K. P. J., \&Sandler, H.M. (April, 2004). Parent role construction for involvement: Interactions among theoretical, measurement and pragmatic issues in instrument development. Paper presented at the Annual Meeting of the American Educational Research Association, San Diego, CA.

Hu, L., \& Bentler, P. M. (1999). Cutoff criteria for fit indexes in covariance structure analysis: Conventional criteria versus new alternatives. Structural Equation Modeling, 6, 1-55.

Izzo, C. V., Weissberg, R. P., Kasprow, W. J., \& Fendrich, M. (1999). A longitudinal assessment of teacher perceptions of parental involvement in children's education and school performance. American Journal of Community Psychology, 27, 817-839.

Kenny, D.A., Kashy, D.A., \& Bolger, N. (1998). Data analysis in social psychology. In D. T. Gilbert, S. T. Fiske, \& G. Lindzey (Eds.), The handbook of social psychology (pp. 233-265)., 4th ed. New York: Oxford University Press.

Kohl, G. O., Lengua, L. J., \& McMahon, R. J. The Conduct Problems Prevention Research Group. (2000). Parent involvement in school: Conceptualizing multiple dimensions and their relations with family and demographic risk factors. Journal of School Psychology, 38, 501-523.

Levy, F., Hay, D. A., Bennett, K. S., \& McStephen, M. B. (2005). Gender differences in ADHD subtype comorbidity. Journal of the American Academy of Child \& Adolescent Psychiatry, 44, 368-376. 
Lincoln Public Schools (2005). 2005-2006 Annual Statistics Handbook: Lincoln Public Schools. http://docushare.lps.org/docushare/dsweb/Get/Document-364139/stats05-06.pdf

Lopes, J. A. (2007). Prevalence and comorbidity of emotional, behavioral and learning problems: A study of 7th-grade students. Education and Treatment of Children, 30, 165-181.

Lopéz, G. R. (2001). The value of hard work: Lessons on parent involvement from an immigrant household. Harvard Educational Review, 71, 416-437.

Ma, X. (1999). Dropping out of advanced mathematics: The effects of parental involvement. Teachers College Record, 101, 60-81.

Machida, S., Taylor, A. R., \& Kim, J. (2002). The role of maternal beliefs in predicting home learning activities in Head Start families. Family Relations, 51, 176-184.

MacKinnon, D. P., Lockwood, C. M., \& Williams, J. (2004). Confidence limits for the indirect effect: Distribution of the product and resampling methods. Multivariate Behavioral Research, 39, 99-128.

Mallinckrodt, B., Abraham, T. W., Wei, M., \& Russell, D.W. (2006). Advance in testing statistical significance of mediation effects. Journal of Counseling Psychology, 53, 372-378.

Manz, P. H., Fantuzzo, J. W., \& Power, T. J. (2004). Multidimensional assessment of family involvement among urban, elementary students. Journal of School Psychology, 42, 461-475.

Marcon, R. A. (1999). Positive relationships between parent school involvement and public school inner-city preschoolers' development and academic performance. School Psychology Review, 28, 395-412.

McGlone, K., Santos, L., Kazama, L., Fong, R., \& Mueller, C. (2002). Psychological stress in adoptive parents of special-needs children. Child Welfare Journal, 81, 151-171.

Miedel, W. T., \& Reynolds, A. J. (1999). Parent involvement in early intervention for disadvantaged children: Does it matter? Journal of School Psychology, 37, 379-402.

Mullaney, L. C., Gill-Hraban, K. A., Sheridan, S. M., Baker, C. M., Kwon, K., \& Daro, P. (2009, August). Examination of parent and teacher engagement in conjoint behavioral consultation. Poster presented at the annual meeting of the American Psychological Association, Toronto, Canada.

Muthén, L. A., \& Muthén, B. O. (1998-2006). Mplus user's guide, 4th ed Los Angeles: Muthén \& Muthén.

Perry, M. A., Fantuzzo, J., \& Munis, P. (2002). Family Involvement Questionnaire Manual. Philadelphia, PA: University of Pennsylvania.

Pesonen, A.-K., Räikkönen, K., Heinonen, K., Komsi, N., Järvenpää, A.-L., \& Strandberg, T. (2008). A transactional model of temperamental development: Evidence of a relationship between child temperament and maternal stress over five years. Social Development, 17, 326-340.

Peugh, J. L. (2010). A practical guide to multilevel modeling. Journal of School Psychology, 48, 85-112.

Räikkönen, K., Pesonen, A.-K., Heinonen, K., Komsi, N., Järvenpää, A.-L., \& Strandberg, T. E. (2006). Stressed parents: A dyadic perspective on perceived infant temperament. Infant and Child Development, $15,75-87$.

Reinke, W. M., Herman, K. C., Petras, H., \& Ialongo, N. S. (2008). Empirically derived subtypes of child academic and behavior problems: Co-occurrence and distal outcomes. Journal of Abnormal Child Psychology, 36, 759-770.

Schofield, H. T., Bierman, K. L., Heinrichs, B., \& Nix, R. L. (2008). Predicting early sexual activity with behavior problems exhibited at school entry and in early adolescence. Journal of Abnormal Child Psychology, 36, 1175-1188.

Sheldon, S. B. (2002). Parents' social networks and beliefs as predictors of parent involvement. The Elementary School Journal, 102, 301-316.

Sheridan, S. M., \& Kratochwill, T. R. (2008). Conjoint behavioral consultation: Promoting familyschool connections and interventions, 2nd ed. New York: Springer.

Spratt, E. G., Saylor, C. F., \& Macias, M. M. (2007). Assessing parenting stress in multiple samples of children with special needs (CSN). Families, Systems, and Health, 25, 435-449.

Shrout, P. E., \& Bolger, N. (2002). Mediation in experimental and nonexperimental studies: New procedures and recommendations. Psychological Methods, 7, 422-445. 
Stevenson, H. W., Chen, C., \& Uttal, D. H. (1990). Beliefs and achievement: A study of Black, White, and Hispanic children. Child Development, 61, 508-523.

Stores, R., Stores, G., Fellows, B., \& Buckley, S. (1998). Daytime behaviour problems and maternal stress in children with Down's syndrome, their siblings, and non-intellectually disabled and other intellectually disabled peers. Journal of Intellectual Disability Research, 42, 228-237.

Suárez-Orozco, C., \& Suárez-Orozco, M. M. (2001). Children of immigration. Cambridge, MA: Harvard University Press.

Trusty, J. (1999). Effects of eighth-grade parental involvement on late adolescents' educational expectations. Journal of Research and Development in Education, 32, 224-233.

U.S. Census Bureau: State and County Quick Facts. Data derived from Population Estimates, 2000 Census of Population and Housing. http://quickfacts.census.gov/qfd/states/31/312800o.html

Vitaro, F., Brendgen, M., Larose, S., \& Trembaly, R. E. (2005). Kindergarten disruptive behaviors, protective factors, and educational achievement by early adulthood. Journal of Educational Psychology, 97, 617-629.

von Gontard, A., Backes, M., Laufersweiler-Plass, C., Wendland, C., Lehmkuhl, G., Zerres, K., et al. (2002). Psychopathology and familial stress - Comparison of boys with Fragile X syndrome and Spinal Muscular Atrophy. Journal of Child Psychology and Psychiatry, 43, 949-957.

Waanders, C., Mendez, J. L., \& Downer, J. T. (2007). Parent characteristics, economic stress and neighborhood context as predictors of parent involvement in preschool children's education. Journal of School Psychology, 45, 619-636.

Walker, H. M., \& Severson, H. H. (1990). Systematic screening for behavior disorders. Longmont, CO: Sopris West.

Walker, J. M. T., Wilkins, A. S., Dallaire, J. R., Sandler, H. M., \& Hoover-Dempsey, K. V. (2005). Parental involvement: Model revision through scale development. The Elementary School Journal, $106,85-104$.

Wong, S. W., \& Hughes, J. N. (2006). Ethnicity and language contributions to dimensions of parent involvement. School Psychology Review, 35, 645-662. 